\title{
MODIFIED SERIES RESISTANCE MODEL - DETERMINATION OF MEAN CONCENTRATION BY INTEGRAL TRANSFORMATION
}

\author{
A. L. Venezuela \\ R. F. Cantão ${ }^{a}$, \\ R. S. Ongaratto ${ }^{b}$, \\ and R. N. Haneda ${ }^{c}$ \\ ${ }^{a}$ Universidade Federal de São Carlos \\ Departamento de Física, Química e Matemática \\ Rodovia João Leme dos Santos, Km 110 \\ Bairro do Itinga \\ CEP: 18052-780, Sorocaba, SP, Brasil \\ alvenez@ufscar.br \\ ${ }^{\mathrm{b}}$ Instituto Nacional da Propriedade Industrial \\ Divisão de Patentes VI \\ Rua Mayrink Veiga, 9, Bairro Centro \\ CEP: 20090-910, Rio de Janeiro, RJ, Brasil \\ 'Centro Paulista de Estudos em Agronegócio \\ Rua 7 de Setembro 2378, Bairro Centro \\ CEP 13560-180, São Carlos, SP, Brasil \\ ABSTRACT \\ There are several mathematical models that describe permeate flow in \\ membrane separation processes. Among these, the series resistance model \\ plays a prominent role. It takes into account membrane strength, \\ concentration polarization, polarized layer and fouling to describe the \\ permeate flow over time. In this work, an analysis of the modified series \\ resistance model was performed, in which the resistance by polarization of \\ the concentration is defined as being directly proportional to the \\ transmembrane pressure. The proportionality constant is given by the \\ product of a specific coefficient of resistance - which is determined by \\ means of experimental data - the thickness of the boundary layer of \\ concentration and the mean concentration. Due to the inability to obtain \\ experimentally the value of the average concentration within the boundary \\ layer of concentration, its simulation is carried out from the conservation \\ equation of the chemical species. Thus, the objective of the present work \\ was to solve the equation of the conservation of chemical species using \\ GITT (Generalized Integral Transform Technique) and apply the modified \\ series resistance model to describe the permeate flow of a solution of \\ dextran through a permeable tube under laminar flow. GITT provided \\ satisfactory results for the mean concentration, verified by comparison with \\ the permeate flow obtained by the series resistance model with experimental \\ results reported in the literature. \\ Received: April 14, 2018 \\ Revised: May 11, 2018 \\ Accepted: May 30, 2018 \\ Keywords: hybrid methods, polarization resistance, cross flow
}

\section{NOMENCLATURE}

c concentration, $\mathrm{m}^{-3} \mathrm{~kg}$

$c_{0} \quad$ inlet concentration, $\mathrm{m}^{-3} \mathrm{~kg}$

$\bar{C}$ average concentration boundary layer, $\mathrm{m}^{-3} \mathrm{~kg}$

$D$ diffusivity, $\mathrm{m}^{2} \mathrm{~s}^{-1}$

$J_{m} \quad$ experimental permeate flux, $m s^{-1}$

$J \quad$ simulated permeate flux (GITT), $\mathrm{m} \mathrm{s}^{-1}$

$J_{0} \quad$ initial permeate flux, $\mathrm{ms}^{-1}$

$J_{Y} \quad$ simulated permeate flux (Yeh, 2003), $\mathrm{m} \mathrm{s}^{-1}$

$k$ mass transfer coefficient, $\mathrm{m} \mathrm{s}^{-1}$

$L \quad$ length of the tube, $m$

$r_{p o} \quad$ pore radius, $m$

$R_{0} \quad$ radius of the tube, $m$

$R_{p} \quad$ resistance of concentration polarization, $m^{-1}$

$R_{f} \quad$ fouling resistence, $m^{-1}$

$u_{0} \quad$ inlet mean axial velocity, $\mathrm{m} \mathrm{s}^{-1}$

$r \quad$ radial coordinate, $m$

$x \quad$ axial coordinate, $m$

\section{Dimensionless}

C concentration $\left(c / c_{0}\right)$

$U$ axial velocity $\left(u / u_{0}\right)$

$V \quad$ radial velocity $\left(v / u_{0}\right)$

$R \quad$ radial coordinate $\left(r / R_{0}\right)$

$X \quad$ axial coordinate $\left(x / R_{0}\right)$

Re Reynolds number, $\rho u_{0} 2 R_{0} / \mu$

Sc Schmidt number, $\mu / \rho D$

$P e \quad$ Péclet number, $R e S c$

$R e_{w} \quad$ Reynolds number in the permeable wall,

$$
\rho J_{0} 2 R_{0} / \mu
$$

\section{Greek symbols}

$\delta \quad$ thickness of concentration boundary layer, $m$

$\delta_{m} \quad$ membrane thickness, m

$\varepsilon \quad$ porosity

$\mu \quad$ dynamic viscosity, $\mathrm{m}^{-1} \mathrm{~kg} \mathrm{~s}^{-1}$

$\rho$ density, $\mathrm{m}^{-3} \mathrm{~kg}$ 
$\Delta p \quad$ transmembrane pressure, $\mathrm{m}^{-1} \mathrm{~kg} \mathrm{~s}^{-2} \quad(=\mathrm{Pa})$

$\tau \quad$ tortuosity

\section{Subscripts}

0 inlet condition

$f \quad$ fouling

lim limiting flux

$m$ average experimental and membrane

$p \quad$ polarization

po pore

$Y \quad$ yeh

\section{INTRODUCTION}

In the membrane separation processes (MSP), especially for ultrafiltration and microfiltration, there is an initial drop in permeate flow over time which is caused by phenomena that limit the transport of the solvent such as concentration polarization, polarized layer and fouling. The resistance in series model is a theoretical model that has been used to describe the phenomena of polarization and fouling and the permeate flux over time (Cheryan, 1998).

The Generalized Integral Transform Technique (GITT) is a hybrid method (numerical and analytical) which is very attractive for the treatment of multidimensional problems. Allied to this, the use of analytical filters, the choice of the most representative basis of the original problem and the use of symbolic manipulation platforms like (Cotta, 1993), contribute to the improvement of this technique. Development of hybrid techniques, which are able to assist in the understanding of the phenomena responsible for the permeate flow drop have been conducted (Venezuela et al., 2009; Kumar et al., 2010).

The objective of this work was to solve by hybrid methods (GITT), the conservation equation of chemical species in cylindrical coordinates to determine theoretical models that will assist the analysis of polarization phenomena responsible for permeate flow decreasing during the microfiltration process.

\section{MATHEMATICAL MODEL}

The development of the methodology for determining the permeate flow follows the steps below.

\section{Modified resistance-in-series model}

The permeate flow, $J$, varying with a pressure is (Paris, 2002):

$$
J(\Delta p)=\frac{\Delta p}{\mu\left(R_{m}+R_{f}+\alpha_{0} \delta \bar{c} \Delta p\right)}
$$

For modeling purposes, a cylindrical membrane with fixed length $L$, radius $R_{0}$ and resistance $R_{m}$ was considered (Yeh, 2003). We assume that through it flows a dextran solution with velocity $u_{0}$, carrying a solute with initial concentration $c_{0}$, diffusivity $D$, viscosity $\mu$, and transmembrane pressure $\Delta p$.

\section{Determination of $J_{\lim }, k$ and $\delta$}

The thickness of the concentration boundary layer, $\delta$, depends on the mass transport coefficient, $k$, which in turn depends on the permeate flow limit, $J_{\lim }$. We have developed a methodology to obtain $J_{\lim }$, which consists of a nonlinear expression with three unknown parameters, determined by nonlinear regression. Using the gel-polarization model along with the aforementioned experimental data, we can obtain the mass transfer coefficient $k$ using a simple linear regression. From the stagnant film theory we evaluate the thickness of concentration boundary layer as $\delta=D / k$ (Zeman and Zydney, 1996). The diffusivity, $D$, according to Yeh et al. (2003).

\section{Obtaining $\bar{c}$, via GITT}

The determination of the mean concentration in the adjacencies of the inner wall of the permeable tube is given by: $\bar{C}=c_{0} \bar{C}$, where $\bar{C}$ is the mean dimensionless concentration defined by:

$$
\bar{C}=\frac{R_{0}^{2}}{L \delta} \int_{0}^{L / R_{0}} \int_{1-\delta / R_{0}}^{1} C(X, R) d R d X
$$

The dimensionless concentration profile, $C=C(X, R)$, for $0 \leq R \leq 1$ and $0 \leq X \leq L / R_{0}$, is determined, by GITT (Venezuela et al., 2009), from the following boundary value problem in the dimensionless form:

$$
\begin{gathered}
V \frac{\partial C}{\partial R}+U \frac{\partial C}{\partial X}=\frac{1}{P e}\left[\frac{1}{R} \frac{\partial}{\partial R}\left(R \frac{\partial C}{\partial R}\right)\right] \\
C(0, R)=1 \\
\left.\frac{\partial C}{\partial R}\right|_{R=0}=0
\end{gathered}
$$

$$
C(X, 1)=\frac{1}{1-\left(J_{0} \delta(X) / D\right)}
$$

To determine the $C$ profile, we must have the following:

(a) The radial, $V=V(R)$, and axial, $U=U(X, R)$, velocity profiles, which are obtained from the work 
of Yuan et al. (1956).

(b) The formulation of the boundary layer thickness of local concentration, $\delta(X)$, is obtained from the work of (Venezuela et al., 2009).

(c) The initial permeate flow, $J_{0}$, is determined using the Kadem-Katchalsky analysis (Zeman and Zydney, 1996):

$$
J_{0}=\frac{\varepsilon r_{p o}^{2}}{8 \mu \tau \delta_{m}} \Delta p
$$

where, $\varepsilon, r_{p o}, \tau$ and $\delta_{m}$ are given in the work of Yeh et al. (2003).

\section{Determination of $\alpha_{0}$ and $R_{f}$}

In order to calculate the specific resistance, $\alpha_{0}$, and the fouling resistance, $R_{f}$, we use:

$$
\frac{\Delta p}{J_{m} \mu}=\left(\alpha_{0} \delta \bar{c}\right) \Delta p+\left(R_{m}+R_{f}\right)
$$

where $J_{m}$ is the experimentally measured permeate flow. The slope, $\alpha_{0} \delta \bar{c}$, and the intercept, $R_{m}+R_{f}$, are determined by standard linear regression. The value of membrane resistance is given in the work of Yeh et al. (2003).

\section{RESULTS AND DISCUSSION}

As mentioned in the text, the determination of the mean concentration in the vicinity of the permeable wall was performed by GITT, according to Venezuela et al. (2009). Thus, the eigenvalues and the normalization integrals were analyzed analytically. The integral coefficients were evaluated numerically. Finally, the resulting system of ordinary differential equations truncated together with the initial conditions was solved numerically. The computational implementation of GITT was carried out on the computer algebra system SAGe (www.sagemath.org, accessed in 12/05/2018).

In this section we present the number of terms (order) for the truncation of the transformed ordinary differentiated system. Simulation results and physical problem data were compared through the behavior of the concentration profile with varying Schmidt and Reynolds numbers. In addition, we compared the results for the permeate flux with experimental data from the literature.

Table 1 presents results for the concentration profile, $C$, as a function of the variable $X$, setting $R=$ 0.98 , for several values of $N$. The values of $C$ were considered with tree decimal places. For this analysis, we can take any value of $R$ in the vicinity of the permeable wall that we will have the same truncation orders. To verify the order of truncation, we fixed a line, for example, in $X=122$, and we find that for $N$
$=5$ we have $C=1.091$, for $N=10$ we have $C=1.078$ and for $N \geq 15$ the values $C=1.072$ are repeated.

Table 1. Convergence results for concentration $C$ varying $X$ in $R=0.98, c_{0}=1.0 \mathrm{~kg} \mathrm{~m}^{-3}$, $u_{0}=0.051 \mathrm{~m} \mathrm{~s}^{-1}, R_{0}=2.510^{-4} \mathrm{~m} \mathrm{e}$ $\Delta p=0.2510^{5} \mathrm{~Pa}$.

\begin{tabular}{ccccc}
\hline \multicolumn{5}{c}{$C$} \\
\hline$X$ & $N=5$ & $N=10$ & $N=15$ & $N=16$ \\
\hline 0 & 1.000 & 1.000 & 1.000 & 1.000 \\
61 & 1.077 & 1.064 & 1.056 & 1.056 \\
122 & 1.091 & 1.078 & 1.072 & 1.072 \\
184 & 1.100 & 1.087 & 1.083 & 1.083 \\
245 & 1.107 & 1.094 & 1.092 & 1.092 \\
306 & 1.113 & 1.101 & 1.099 & 1.099 \\
367 & 1.117 & 1.106 & 1.105 & 1.105 \\
428 & 1.121 & 1.111 & 1.110 & 1.110 \\
490 & 1.125 & 1.115 & 1.114 & 1.114 \\
551 & 1.128 & 1.119 & 1.118 & 1.118 \\
612 & 1.131 & 1.122 & 1.121 & 1.121 \\
\hline
\end{tabular}

Figure 1 show the results of concentration, $C$, near to the surface tube $(R=0.98)$ as a function of the dimensionless axial position, $X$. The values correspond to Schmidt, Sc, are $1.010^{4}, 0.810^{4}$ and $0.610^{4}$; a concentration increase tendency is observed next to the wall as a function of an increase of the Schmidt number. $S c$ and diffusivity $D$ are inversely proportional, that is, the increase of $S c$ may be associated to the decreasing of the diffusion coefficient. The results obtained from the integral transform are in agreement with this type of physical behavior.

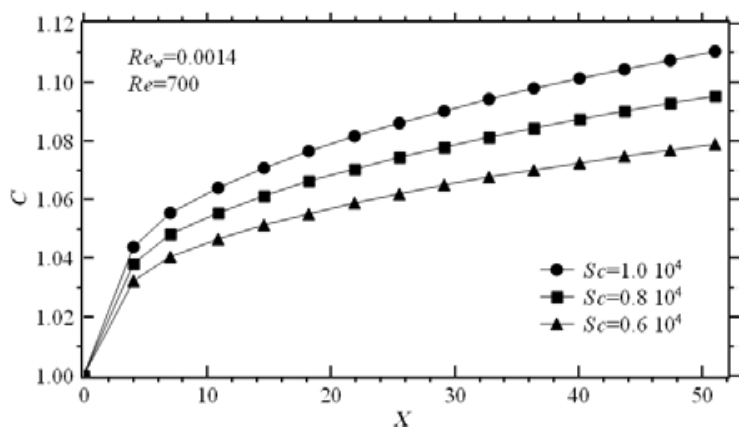

Figure 1. Schmidt's number effect over the concentration profile depending on the dimensionless axial position, $X$, near the permeable wall $(R=0.98)$ for $N=15, R e=700$ and $R e_{w}=0.0014$.

Figure 2 illustrates when the Reynolds number decreases, there is an increase in solute concentration near the surface of the tube. In this case, it is expected that, with decreasing Reynolds number, the 
mass transfer mechanism decreased, causing an increase in the rate limitation and the concentration of solute near the porous surface. In this case, the behavior of the concentration profile is in line with the expected physical patterns.

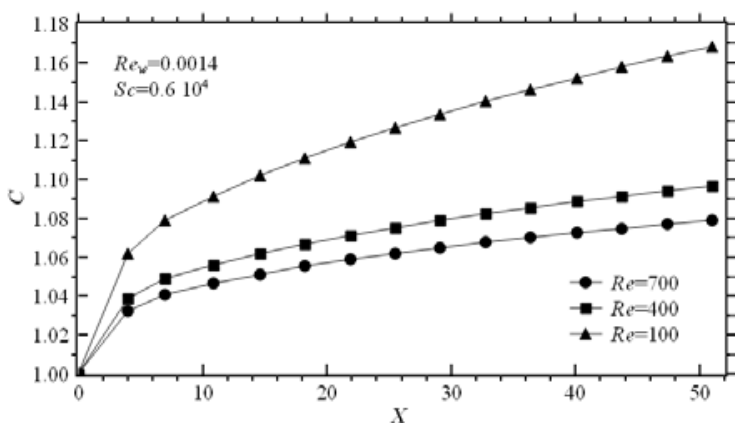

Figure 2. Reynolds's number effect over the concentration profile depending on the dimensionless axial position, $X$, near the permeable wall $(R=0.98)$ for $N=15, S_{C}=0.610^{4}$ and $R e_{w}=0.0014$.

Permeate flux results obtained with GITT, $J$, were compared with experimental data, $J_{m}$, and simulated data, $J_{Y}$, as reported by Yeh et al. (2003). Table 2-a and 2-b shows that the relative differences $D_{1}=\left|J-J_{m}\right| / J_{m} \quad$ and $\quad D_{2}=\left|J_{Y}-J_{m}\right| / J_{m} \quad$ are adequate.

In Table 2-a the relative differences, $D_{1}$ and $D_{2}$, show that the permeate flow results $J$ and $J_{Y}$ have good approximation with the experimental permeate flow results, $J_{m}$. However, in Table 2-b, $D_{1}$ and $D_{2}$ illustrate that the permeate flow results $J$ have a better approximation than $J_{Y}$, when compared with $J_{m}$. Therefore, for $c_{0}=10.0 \mathrm{~kg} \mathrm{~m}^{-3}$, we have that the experimental permeate flux, $J_{m}$, is best represented by $J$ and, for $c_{0}=1.0 \mathrm{~kg} \mathrm{~m}^{-3}, J$ and $J_{Y}$ are good representatives of $J_{m}$.

Table 2. (a) $c_{0}=1.0 \mathrm{~kg} \mathrm{~m}^{-3}$ and (b) $c_{0}=1.0 \mathrm{~kg} \mathrm{~m}^{-3}$. Comparison amongst experimental. $J_{m}$. and simulated data from Yeh et al. (2003), $J_{Y}$, and the results obtained with the modified resistance in series model, $J$, depending on pressure, $\Delta p$. For each case relative differences are also shown. $J, J_{m}, J_{Y}\left(10^{6} \mathrm{~m} \mathrm{~s}^{-1}\right)$.

(a)

\begin{tabular}{c|c|c|c|c|c|c}
\hline \multirow{2}{*}{$\begin{array}{c}\Delta p \\
\left(10^{-5} \mathrm{~Pa}\right)\end{array}$} & \multirow{3}{*}{$\begin{array}{c}u_{0} \\
\left(\mathrm{~m} \mathrm{~s}^{-1}\right)\end{array}$} & \multicolumn{3}{|c|}{$c_{0}=1.0 \mathrm{~kg} \mathrm{~m}^{-3}$} & \multicolumn{2}{c}{ Rel. Diff. } \\
\cline { 3 - 7 } & & $J$ & $J_{m}$ & $J_{Y}$ & $\begin{array}{c}D_{1} \\
(\%)\end{array}$ & $\begin{array}{c}D_{2} \\
(\%)\end{array}$ \\
\hline 0.45 & & 3.327 & 3.331 & 4.433 & 0.1 & 24.9 \\
0.65 & & 4.150 & 4.225 & 4.922 & 1.8 & 14.2 \\
0.95 & 0.051 & 4.881 & 4.838 & 5.131 & 0.9 & 5.7 \\
1.15 & & 5.165 & 5.078 & 5.311 & 1.7 & 4.4 \\
1.35 & & 5.359 & 5.311 & 5.131 & 0.9 & 3.5 \\
\hline 0.45 & \multirow{2}{*}{0.102} & 3.694 & 3.682 & 4.493 & 0.3 & 18.0 \\
0.65 & 4.741 & 4.861 & 5.201 & 2.5 & 6.5
\end{tabular}

\begin{tabular}{c|c|c|c|c|c|c}
0.95 & & 5.723 & 5.767 & 5.875 & 0.8 & 1.8 \\
1.15 & & 6.126 & 6.114 & 6.215 & 0.2 & 1.6 \\
1.35 & & 6.411 & 6.391 & 6.459 & 0.3 & 1.1 \\
\hline 0.45 & & 3.688 & 3.623 & 4.977 & 1.8 & 27.2 \\
0.65 & & 4.871 & 4.919 & 5.705 & 0.9 & 13.8 \\
0.95 & 0.153 & 6.102 & 6.175 & 6.469 & 1.2 & 4.5 \\
1.15 & & 6.653 & 6.745 & 6.869 & 1.4 & 1.8 \\
1.35 & & 7.057 & 7.012 & 7.113 & 0.6 & 1.4 \\
\hline 0.45 & & 4.135 & 4.044 & 5.446 & 2.2 & 25.7 \\
0.65 & & 5.505 & 5.633 & 6.384 & 2.3 & 11.8 \\
0.95 & 0.204 & 6.940 & 7.041 & 7.323 & 1.4 & 3.8 \\
1.15 & & 7.572 & 7.617 & 7.772 & 0.6 & 2.0 \\
1.35 & & 8.038 & 8.024 & 8.106 & 0.2 & 1.0 \\
\hline
\end{tabular}

(b)

\begin{tabular}{c|c|c|c|c|c|c}
\hline \multirow{2}{*}{$\begin{array}{c}* \\
\left(10^{-5} \mathrm{~Pa}\right)\end{array}$} & \multirow{2}{*}{$u_{0}$} & \multicolumn{2}{|c|}{$c_{0}=10.0 \mathrm{~kg} \mathrm{~m}^{-3}$} & \multicolumn{2}{c}{ Rel. Diff. } \\
\cline { 4 - 7 } & & $J$ & $\mathrm{~J} \mathrm{~s}_{m}$ & $J_{Y}$ & $\begin{array}{c}D_{1} \\
(\%)\end{array}$ & $\begin{array}{c}D_{2} \\
(\%)\end{array}$ \\
\hline 0.45 & & 2.087 & 2.092 & 2.163 & 0.2 & 3.3 \\
0.65 & & 2.354 & 2.328 & 2.355 & 1.1 & 1.1 \\
0.95 & 0.051 & 2.529 & 2.512 & 2.527 & 0.7 & 0.6 \\
1.15 & & 2.586 & 2.551 & 2.597 & 1.4 & 1.8 \\
1.35 & & 2.621 & 2.636 & 2.653 & 0.6 & 0.7 \\
\hline 0.45 & & 2.281 & 2.252 & 2.338 & 1.3 & 3.7 \\
0.65 & & 2.558 & 2.590 & 2.554 & 1.3 & 1.4 \\
0.95 & 0.102 & 2.735 & 2.738 & 2.723 & 0.1 & 0.5 \\
1.15 & & 2.792 & 2.782 & 2.799 & 0.4 & 0.6 \\
1.35 & & 2.827 & 2.825 & 2.859 & 0.1 & 1.2 \\
\hline 0.45 & & 2.481 & 2.487 & 2.653 & 0.2 & 6.3 \\
0.65 & & 2.877 & 2.864 & 2.919 & 0.4 & 1.9 \\
0.95 & 0.153 & 3.148 & 3.148 & 3.138 & 0.1 & 0.3 \\
1.15 & & 3.237 & 3.206 & 3.250 & 1.0 & 1.4 \\
1.35 & & 3.294 & 3.277 & 3.317 & 0.5 & 1.2 \\
\hline 0.45 & & 2.753 & 2.788 & 3.081 & 1.2 & 9.5 \\
0.65 & & 3.293 & 3.345 & 3.423 & 1.6 & 2.3 \\
0.95 & 0.204 & 3.696 & 3.683 & 3.715 & 0.4 & 0.9 \\
1.15 & & 3.834 & 3.831 & 3.834 & 0.1 & 0.1 \\
1.35 & & 3.922 & 3.887 & 3.940 & 0.9 & 1.4 \\
\hline
\end{tabular}

\section{CONCLUSIONS}

Polarized concentration resistance was determined with the help of computational simulations of the mean concentration of solute within the boundary layer, via GITT. Next, permeate flux was calculated using the modified resistance-inseries model. Relative errors are satisfactory. when compared with the literature.

Thus, GITT can be regarded as an efficient tool to evaluate the permeate flow associated with microfiltration processes.

\section{REFERENCES}

Cheryan, M., 1998, Ultrafiltration and Microfiltration Handbook, CRC Press, Boca Raton, 
Florida, 2nd edition.

Cotta, R. M., 1993, Integral Transforms in Computational Heat and Fluid Flow, CRC Press, Boca Raton, Florida.

Kumar, V., Pandey, R. N., and Upadhyay, S. N., 2000, Exact Solution of Convective Mass Transfer Model for Calcium Response of Endothelium, Mathematical Problems in Engineering, Vol. 5, pp. 361-377.

Özisik, M. N., 1980, Heat Conduction, John Wiley, New York.

Paris, J., Guichardon, P., and Charbit, F., 2002, Transport Phenomena in Ultrafiltration: a New TwoDimensional Model Compared with Classical Model, Journal Membrane Science, Vol. 207, pp. 43-58.

Venezuela, A. L., Guerrero, J. P., and Fontes, S. R., 2009, Hybrid Modeling of Convective Laminar Flow in a Permeable Tube Associated with the CrossFlow Process, Communications in Nonlinear Science and Numerical Simulation, Vol. 14, pp. 795-810.

Zeman, L. J., and Zydney, A. L., 1996, Microfiltration and Ultrafiltration - Principles and Applications, Marcel Dekker, New York.

Yeh, H. M., Wu, H. P., and Dong, J. F., 2003, Effects of Design and Operating Parameters on the Declination of Permeate Flux for Membrane Ultrafiltration Along Hollow-Fiber Modules, Journal of Membrane Science, Vol. 213, pp. 33-44.

Yuan, S. W., Funkelstein, A. B., and Brooklyn, N. Y., 1956, Laminar Pipe Flow with Injection and Suction through a Porous Wall, Transactions of the ASME, Vol. 78, pp. 719-724. 